\title{
Development of a Compact Matrix Converter
}

\author{
J. Bauer
}

This paper deals with the development of a matrix converter. Matrix converters belong to the category of direct frequency converters. A converter does not contain DC-link and the output voltage is provided by direct switching of voltage from the input phases. This is enabled by 9 bidirectional switches, which are provided by anti-serial connection of 18 IGBT transistors. The absence of a DC-link is great advantage of the matrix converter, but it also increases the requirements on the converter control. For this reason a new prototype of a matrix converter is being developed with sophisticated modern components (FPGA, Power PC) equipped in the control part of the converter. The converter will be used for testing new control algorithms and commutation methods.

Keywords: Matrix converter, direct frequency converter, filter design.

\section{Introduction}

The beginnings of the Matrix Converter date back to the late 1970s. Nowadays, the name "Matrix Converter" is used to label any power topology that can be organized into sub blocks placed in a matrix shape. In this paper "Matrix Converter" refers to the symmetrical $3 \times 3$ topology provided by nine bidirectional switches. The converter belongs to the direct frequency converter category. The output voltage is provided by direct switching of the input phases to the output phases. This means that the converter does not need a DC-link capacitor. The absence of a DC-link capacitor is one of the main advantages of the matrix converter. However it also means that the output voltage amplitude is limited by $86,6 \%$ voltage amplitude on the input. Higher voltages can be achieved with overmodulation, which causes input current distortion. The other advantages of the converter compared to a conventional indirect frequency converter are power factor regulation; work in all four quadrants; its high dynamics; sinusoidal current consumption; nearly sinusoidal output voltage waveform, with low harmonic content and high efficiency. The main disadvantages include: number of semiconductor devices, limited output voltage amplitude, and a complicated regulation algorithm.

\section{The projected Matrix Converter}

A simplified block diagram of the converter is shown in Fig. 1. To design the converter it is necessary to know some of its basic characteristics. The converter is supplied from the ordinary 230/400 V AC network and the output current is assumed to be circa $25 \mathrm{~A}$. The other components of the converter are designed on the basis of these parameters. Details of the individual blocks are provided in the following subsections.

\subsection{Power part}

As was stated above the power part of the converter is made of nine bidirectional switches. Each switch consists of two IGBT transistors that are connected anti-serially with a common emitter. This means that the whole power part of the converter is carried out of 18 discreet IGBT transistors. In accordance with the output current value of $25 \mathrm{~A}$, IGBTs in the SOT227 package with continuous collector current $70 \mathrm{~A}$

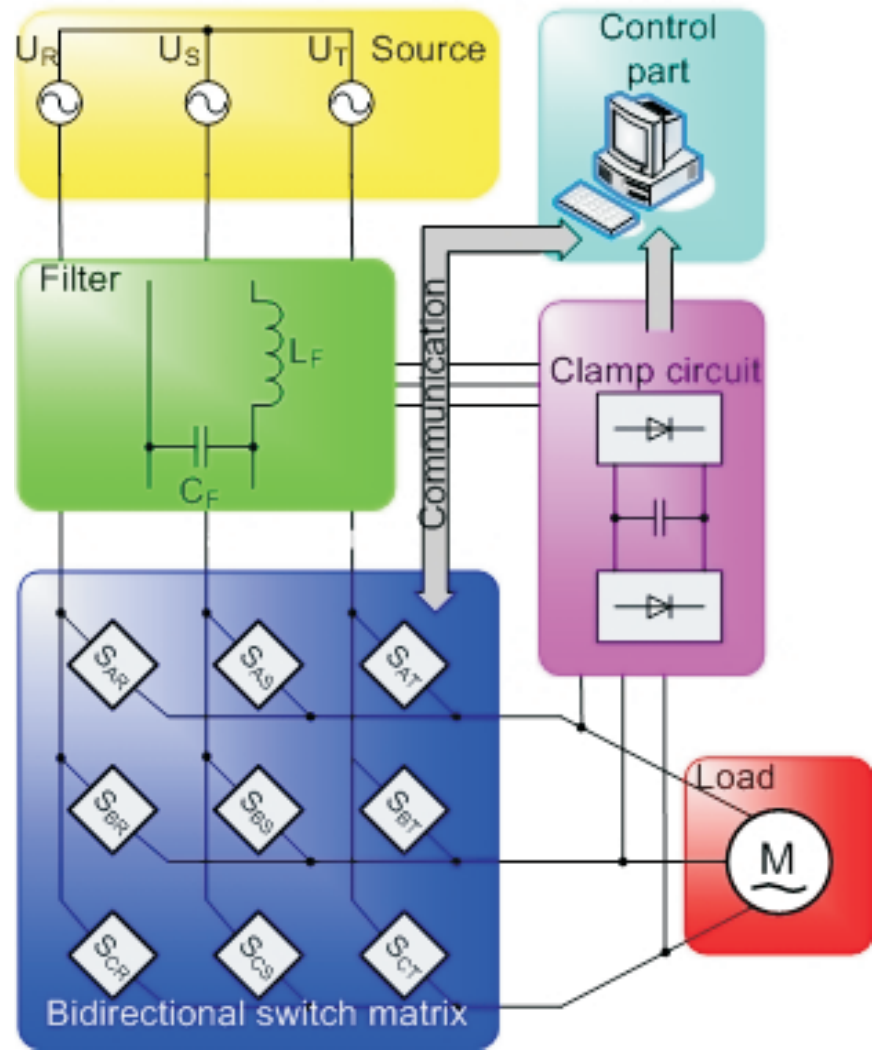

Fig. 1: Block diagram of matrix converter

were chosen. The calculated power losses of $4 \%$ in the IGBTs modules correspond to the estimated power of $20 \mathrm{~kW}$. This means the radiator must cool approximately $P_{z}=800 \mathrm{~W}$. We therefore chose a radiator with dimensions $125 \times 300 \times 135 \mathrm{~mm}$ with fans on both sides.

The placement of the transistors is shown in Fig. 2.

It was decided to connect the modules according to Fig. 2. First, the links are traversed due to the symmetry of the phases and then the modules are divided to 3 groups of six, where each group of six represents one output phase. The connections of each group of six are realized by 4 layer printed circuit board. The advantages of this solution are: firstly, the IGBT protection circuits are realized on the board as snubber capacitors, varistors and a clamp circuit. Secondly, 


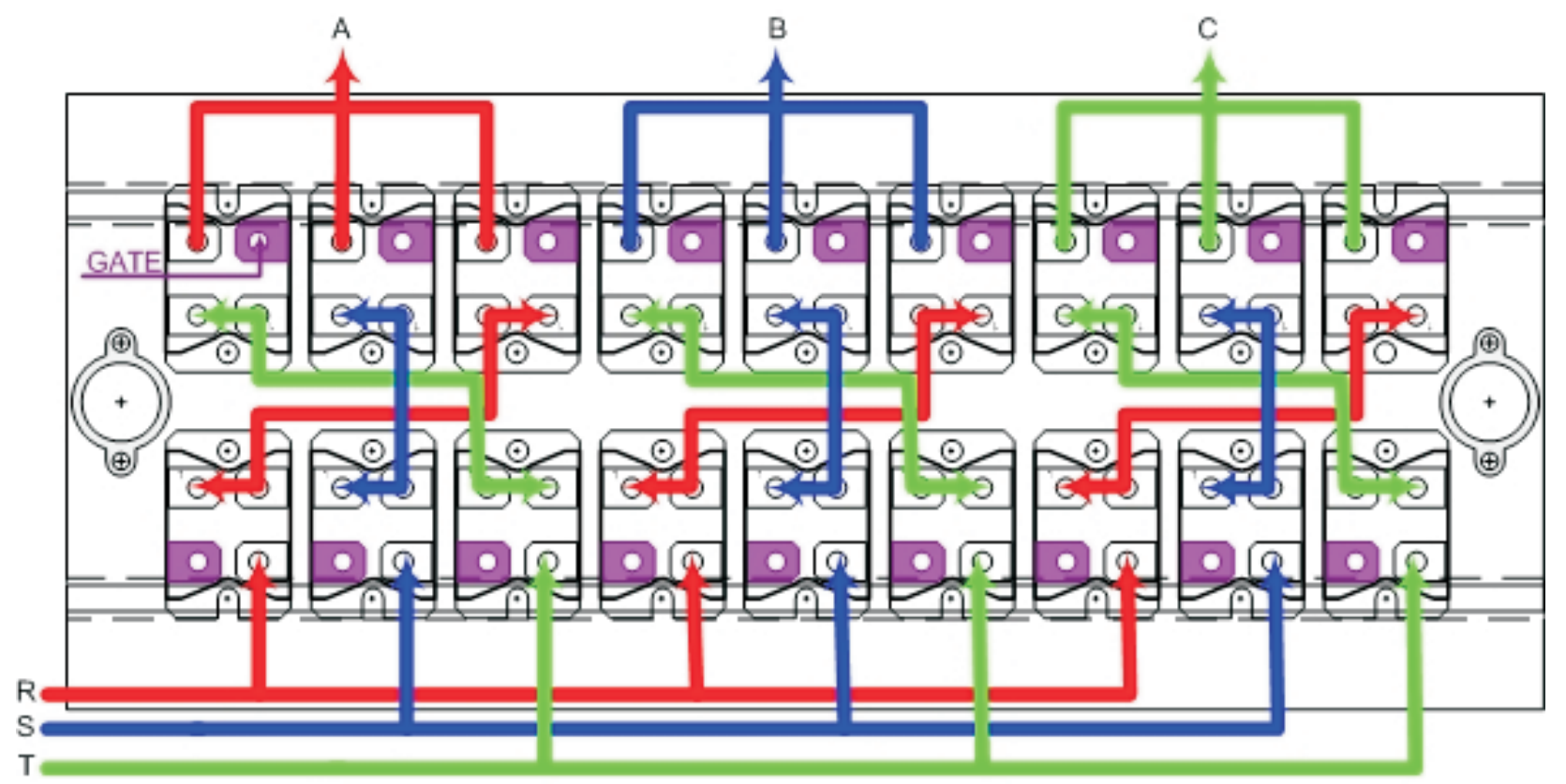

Fig. 2: Placement of the modules on the radiator

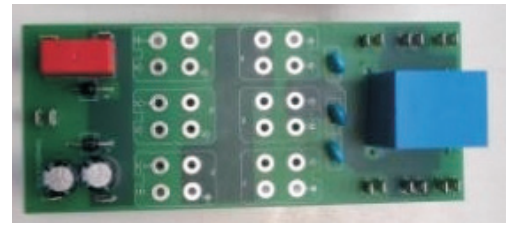

Fig. 3: Connection board

when a transistor breaks down, it can be easily replaced. The manufactured board is shown in Fig. 3 .

\subsection{Input filter}

Nowadays the input filter is an important part of electronic devices. The advantages offered by modern regulated electrical drives need not to be mentioned here, but on the other hand semiconductor converters are among the worst polluters in the supply network. We therefore decided to equip the converter with two filters. The first of these is a commercial filter with a frequency range from $150 \mathrm{kHz}$ to $30 \mathrm{MHz}$

The second filter is for the low frequency distortions caused by the switching frequency. This filter is realized as a simple LC combination, which forms low pass. The design of the filter proceeds from the converter switching frequency $f_{\mathrm{s}}=15 \mathrm{kHz}$. The resonant frequency of the filter must therefore be chosen to provide sufficient distance for adequate attenuation of the switching frequency. The resonant frequency of the filter is therefore chosen as $f_{\text {res }}=1 \mathrm{kHz}$. The design of the filter is a compromise between the value of the capacity and the inductance. A higher capacity at the input of the converter has a positive influence on the voltage quality, but it also requires higher inductance to obtain the required fres. Other points of the design features are the cost of the components and the technical abilities of the manufacturers. We therefore chose a 3 phase coil with $L_{\mathrm{F}}=1 \mathrm{mH}$ and from (1)

$$
f_{\text {res }}=\frac{2}{2 \pi \sqrt{L C}}=1000 \mathrm{~Hz}
$$

we calculated the capacity $C_{\mathrm{F}}=25 \mu \mathrm{F}$ for the connecting the capacitors to the star. The required capacity decreases three times, when the capacitors are connected to $\Delta$. A filter designed in this way is simple, but it is susceptible to resonances and magnifies the amplitudes in the region near the resonant frequency. For this reason, damping circuits were considered for the filter. Two variants of the filter with damping are shown in Fig. 4. Fig. 5 shows the transfer functions of the filter types.
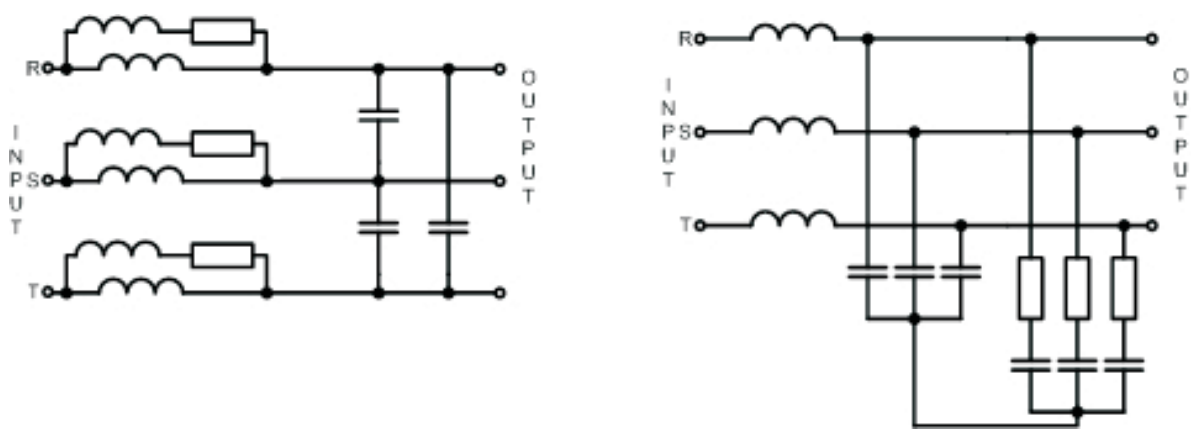

Fig. 4: Filter variants 


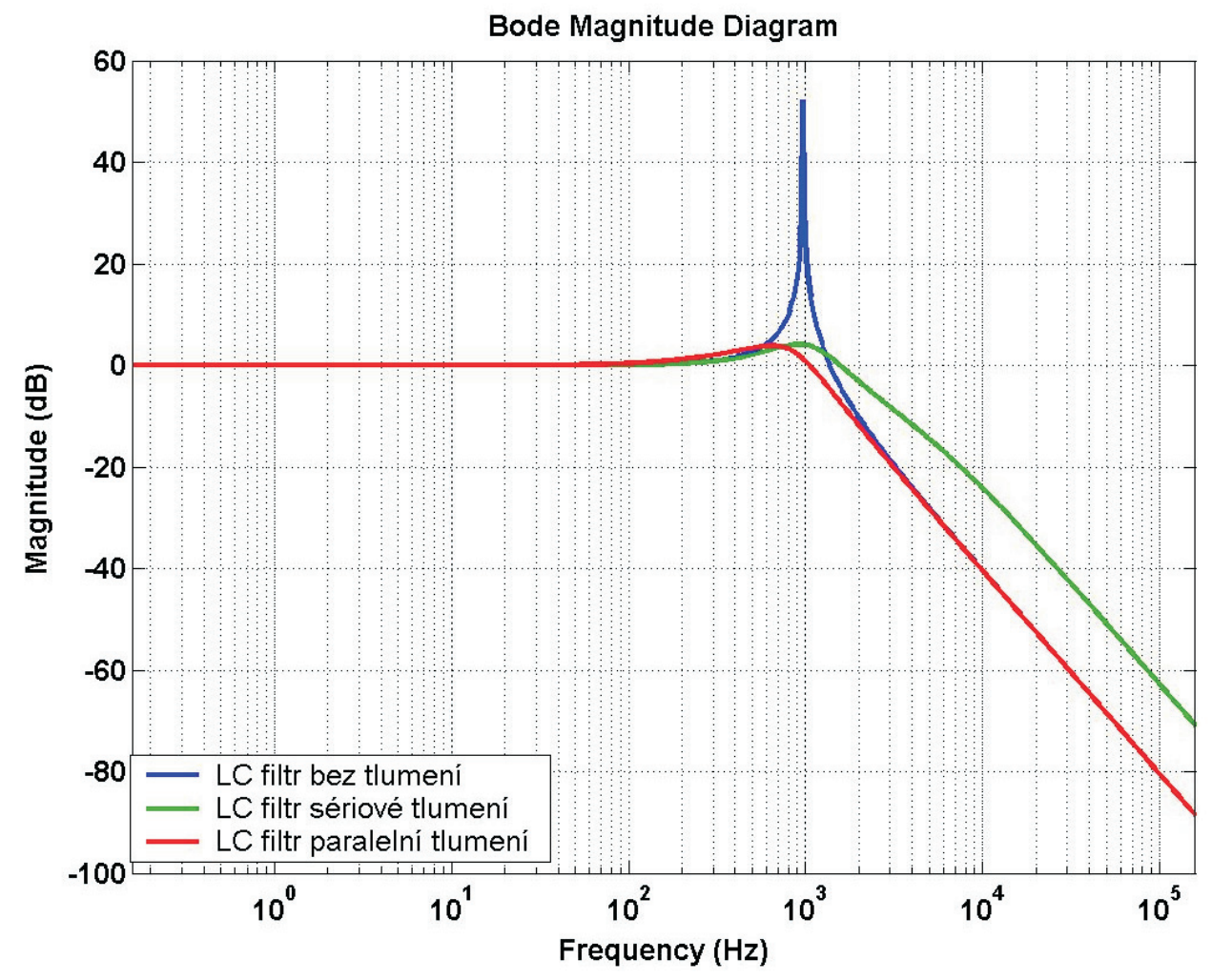

Fig. 5: Transfer function

Fig. 5 shows the area of the filter magnification without damping and the difference between series and parallel damped filters. The parallel damped filter has better characteristics, but it also has higher losses in the damping circuit too. We therefore chose the variant with the series damped filter, which has lower losses in damping circuit and smaller capacitors. The filter is realized by $L_{\mathrm{F}}=1 \mathrm{mH} ; C_{\mathrm{F}}=9 \mu \mathrm{F}$ and damping with values calculated in (2) and (3).

$$
\begin{aligned}
& R_{\mathrm{SD}}=\sqrt{\frac{L_{\mathrm{F}}}{C_{\mathrm{F}}}}=\sqrt{\frac{1 \mathrm{mH}}{9 \mu \mathrm{F}}}=10 \Omega, \\
& L_{\mathrm{SD}}=\frac{2}{15} L_{\mathrm{F}}=\frac{2}{15} 150 \mathrm{mH} .
\end{aligned}
$$

Fig. 6 shows the filter simulation results without damping (left part of the figure) and for the chosen filter with series damping (right part of the figure).

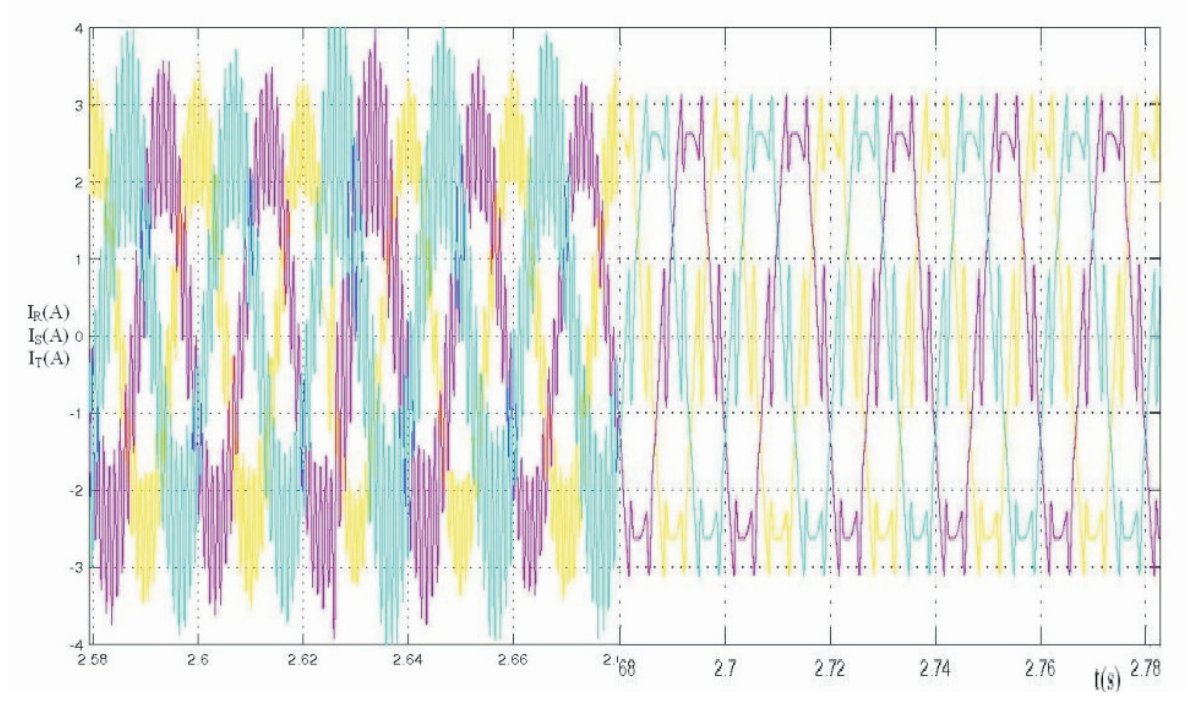

Fig. 6: Input current waveforms 


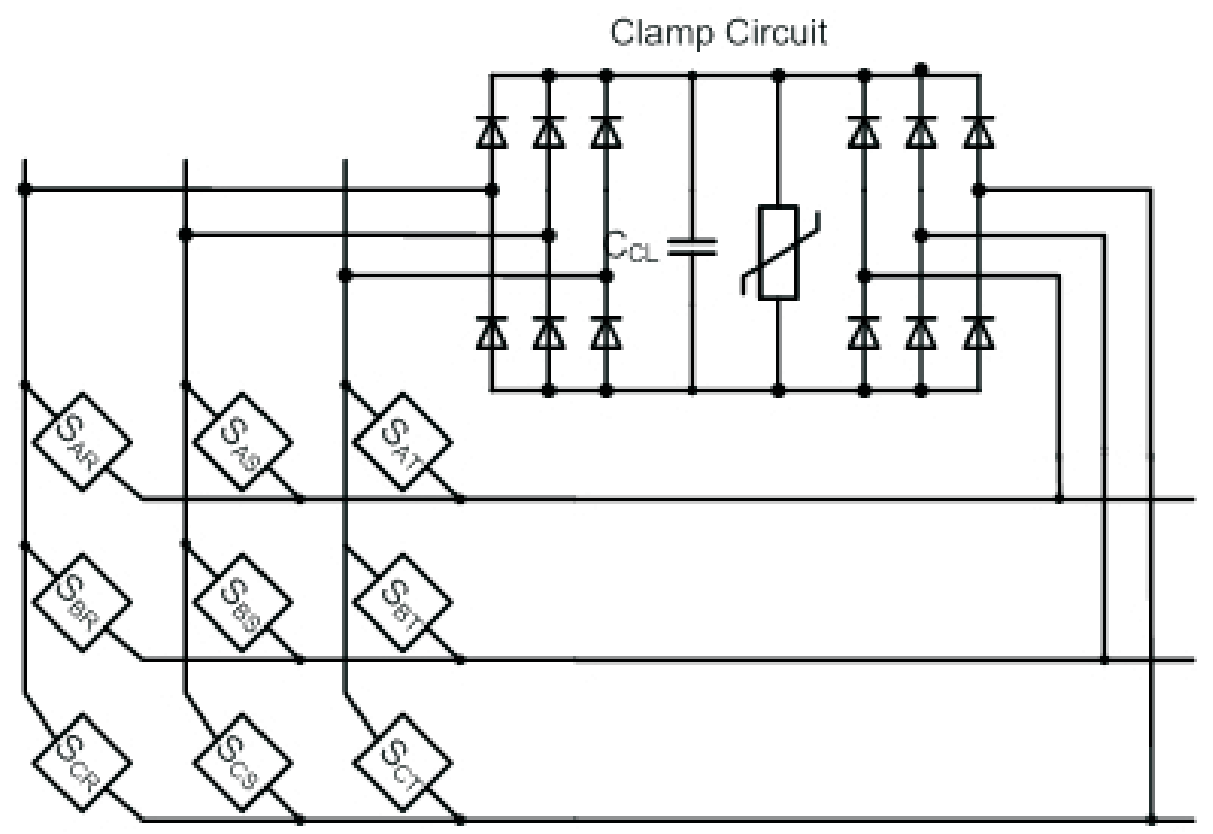

Fig. 7: Clamp circuit

\subsection{Protection circuit}

The converter is for use in the design of new control algorithms, modulation and commutation methods. For this reason the protection circuits were included in the design of the converter.

First there are the hardware protection circuits, which are included in the connection board in Fig. 3. One is realized by varistors, which are connected parallel to each bidirectional switch. Their task is to protect the IGBT modules against surges. The second is realized by a clamp circuit. The clamp circuit in Fig. 7 is made of two diode rectifiers connected to the input and output phases. Between these rectifiers we connect the capacitor and varistor. The task of the capacitor in clamp circuits is to accumulate the energy, which is stored in the load inductances, in the case of a bad switching combination or voltage failure. The task of the varistor is to discharge the capacitor.

The varistors must be able to consume the energy that is in the load inductance. In [1] there is a derivation of the equation for calculating the approximate energy that needs to be taken from the motor load.

$$
\Delta E_{\mathrm{M}}=\frac{1}{2} \frac{P_{\mathrm{N}}}{i_{\mathrm{k}} \omega_{\mathrm{s}} \cos \varphi_{\mathrm{N}} \eta_{\mathrm{N}}} .
$$

Where $P_{\mathrm{N}}$ is the nominal power of the motor, the power factor $\cos \varphi$ of the motor is between $0.7-0.85$, the efficiency of the motor is $\eta$ between $0.7-0.9$ and $i_{\mathrm{k}}$ is the coefficient of the motor run-up multiple 3.5-7.5. So the range of the accumulated energy is between:

$$
\frac{P_{\mathrm{N}}}{3805} \leq \Delta E_{\mathrm{M}} \leq \frac{P_{\mathrm{N}}}{1077} .
$$

Secondly there is software protection. Each IGBT module has its own driver circuit. The role of the driver is to amplify the switching signal and it is also used for monitoring the transistor states. This information is sent back to the switching pattern board. So when an error occurs, the switching pattern generator will immediately block all pulses.

\subsection{Switching pattern generator board}

The control system of the converter is realized by driver boards, switching pattern generators and a pilot controller (Fig. 8). Each bidirectional switch requires two control signals and puts out 4 signals indicating its state and current direction. This means that there are 54 signals handled by the controller at any moment. The control system has to work in real time in order to generate the switching pulses and to receive information at maximum frequency. On the other

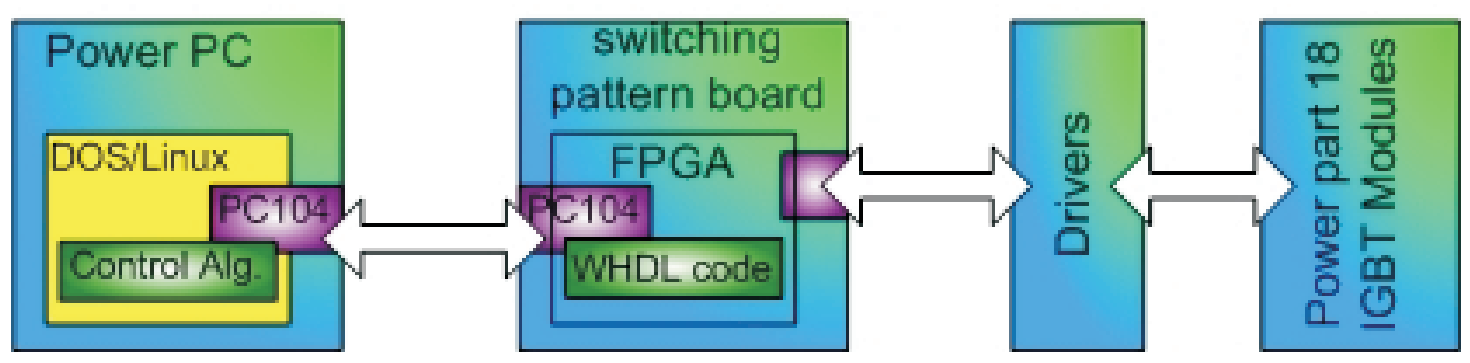

Fig. 8: Controller design 


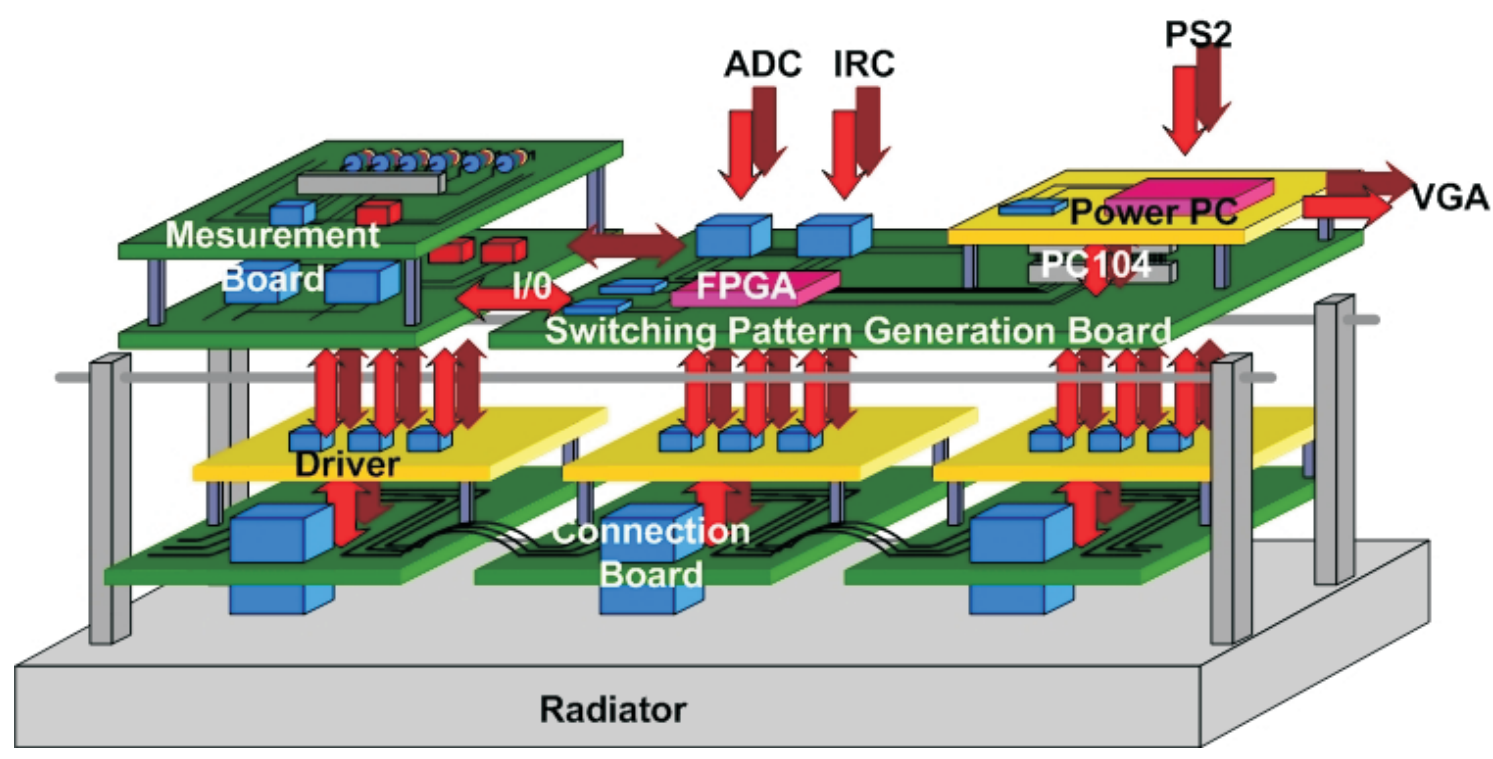

Fig. 9: Placement of the boards

hand, the control system should be as simple as possible for reasons of reliability, and should be compatible with standard industry interfaces. To fulfil these requirements and to enable direct communication between the pilot controller unit and the driving pulse generator, it was decided to connect the generator directly to a standard system bus. ISA, PCI, and PCI Express are the most widespread ones. The ISA is the oldest bus, easy to handle and its throughput is sufficient for this application. Although there are nowadays almost no mass-market PCs with an ISA bus, the situation in the area of industrial computers is completely different. Many producers offer industrial PC boards in PC104, EPIC, and EBX format for embedded applications. For the matrix converter controller a combination of a custom EBX main board and a PC104 processor board was selected.

The switching pattern board works as a modulator. It contains digital interfaces (PC104, speed sensor, ISP, JTAG, RS232, PS2, switching pulses, error lines) as well as an analog interface (sigma-delta and voltage-frequency converters). All digital signals are handled by a core FPGA device (Cyclone II), which is situated on a board. FPGA has stored in it the code for switching pulse generation, basic error detection, diagnostics and also the service routines for all peripheries, including the PC 104 bus. A great advantage of this solution is that in the event of a breakdown the whole converter is stopped in nanoseconds by a change to one input pin of FPGA. A pilot controller is connected via the PC 104 bus. The POWER PC module from RTD acts as the controller here. As far as the system is concerned, DOS will run for the initial testing in POWER PC. Linux has become very popular in recent years will be employed in the final implementation.

For simplest modulation algorithm execution, it is necessary to be informed about 2 input voltage levels and 2 output current levels. The converter is therefore equipped with 4 LEM current sensors on the input and output current measurement and 3 LEM voltage sensors on the input voltage measurement. The output voltages are measured using a resistor voltage divider. All signals will be transmitted to FPGA and will be used for testing and developing of more sophisticated control algorithms.

\section{Matrix converter realization}

The main task is to make the converter as compact and as modular as possible. Many parts of the converter e.g., driver boards, connection boards, switching pattern generation board, board for measurements and for sensor signal adjustments have been specially developed for this converter. The placement of the boards fulfills the requirements on modularity, and the boards are easy to remove. The proposed design of the position of the control part boards is shown in Fig. 9.

The whole structure is mounted on the radiator. The dimensions of the converter chassis are $600 \times 350 \times 250 \mathrm{~mm}$. The dimensions have been chosen on the basis of other converters in our laboratory. Fig. 10 shows the current state of the converter development. All components of the power part have been mounted on the chassis. The connection boards and the driver board have been manufactured, and fit with the electronic parts. The power part of the converter is now being wired and the other boards will be manufactured.

\section{Conclusion}

The proposed new matrix converter system configuration promises many improvements. However, the real impact of the proposed system will be evaluated when the whole system is completed.

\section{Acknowledgements}

The research described in this paper has been supervised by Doc. Ing. J. Lettl CSc. and Ing. S. Flígl PhD, FEE CTU in Prague.

\section{References}

[1] Flígl, S.: Matrix Converter in Hybrid Drives. PhD Thesis, CTU FEE, 2006. 


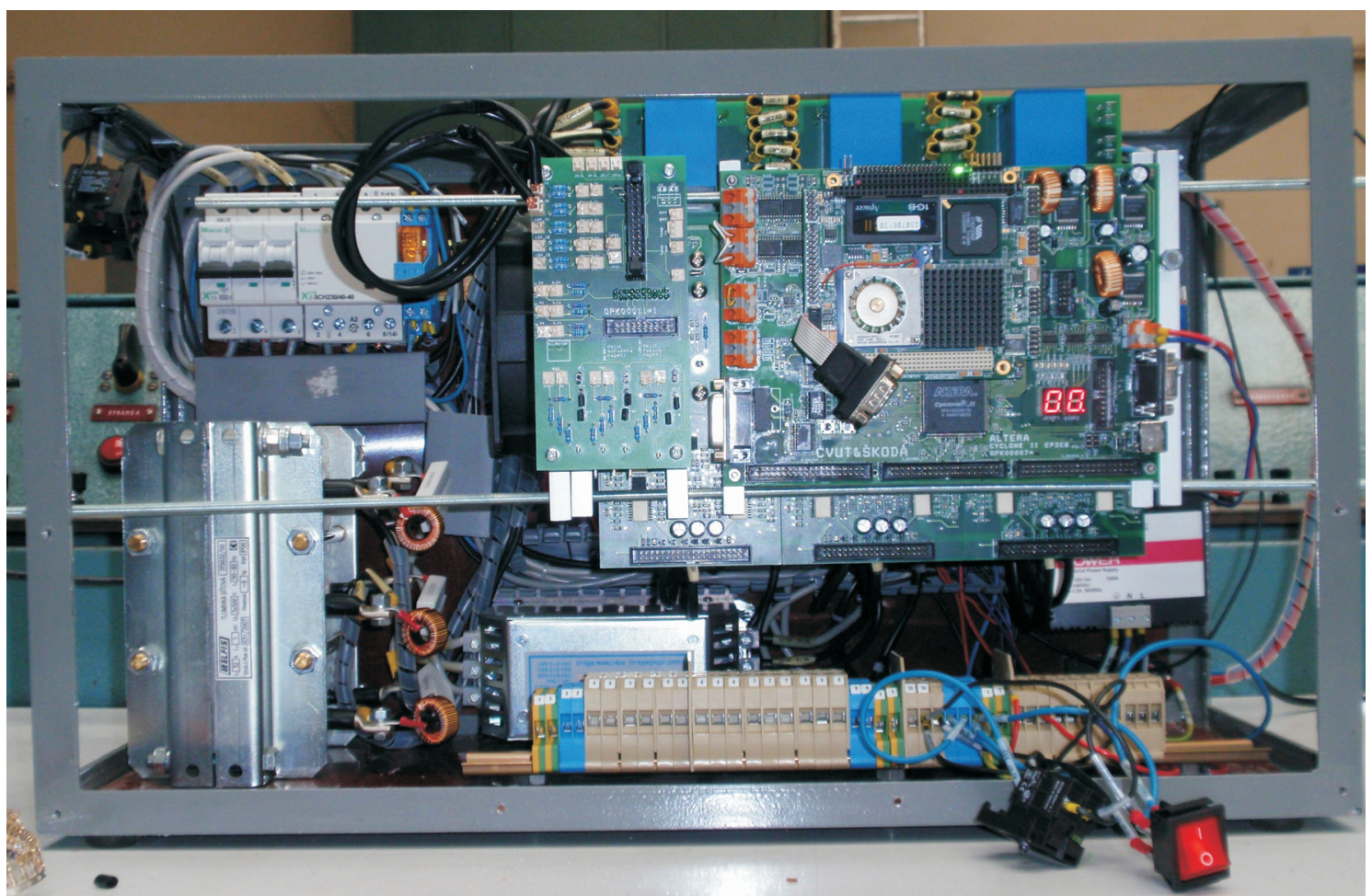

Fig. 10: Current sate of the converter realization

[2] Nielsen, P., Blaabjerg, F., Pedersen, J. K.: Novel Solutions for Protection of Matrix Converter to Three Phase Induction Machine. Proceedings of IEEE-IAS '97, 1997, p. 1447-1454.

[3] Bauer, J.: Konstrukce kompaktního maticového měniče a jeho dimenzování. Diploma Thesis, CTU FEE, 2007.

[4] Bednář, M., Flígl, S., Lettl, J.: Switching Pattern Generation Board for Compact Matrix Converter. Proceedings of TRANSCOM '07, 2007.

\section{Jan Bauer}

e-mail: bauerj1@.fel.cvut.cz

Department of Electric Drives and Traction

Czech Technical University in Prague

Faculty of Electrical Engineering

Technická 2

16627 Prague, Czech Republic 